\title{
EFFECT OF HYBRID FIBER REINFORCEMENT ON CORROSION- INDUCED DAMAGE OF REINFORCED CONCRETE
}

\author{
WILSON NGUYEN ${ }^{\dagger}$, GABRIEL JEN ${ }^{\dagger}$, JACOB F. DUNCAN ${ }^{\dagger, *}$ AND \\ CLAUDIA P. OSTERTAG ${ }^{\dagger}$ \\ ${ }^{\dagger}$ University of California, Berkeley \\ Berkeley, CA USA \\ e-mail: willnguyen@berkeley.edu (W. Nguyen) \\ e-mail: gjen@berkeley.edu (G. Jen) \\ e-mail: jduncan@berkeley.edu (J.F. Duncan) \\ e-mail: ostertag@ce.berkeley.edu (C.P. Ostertag)
}

Key Words: Hybrid fiber-reinforced concrete, Self-consolidating concrete, Reinforced concrete, Corrosion, Durability, Splitting crack

\begin{abstract}
The corrosion of steel reinforcing bars in concrete structures is a primary durability concern in aging infrastructure. Cracks caused by the internal growth of corrosion products increase the permeability of the matrix and degrade the designed capacity of structural elements. In this longterm study, two types of hybrid fiber-reinforced concrete (HyFRC) - a baseline HyFRC and a selfconsolidating HyFRC (SC-HyFRC) - are investigated for serviceability enhancement under a twostage corrosion model (time to corrosion initiation and damage during corrosion propagation). HyFRC, which contains a synergistic blend of microfibers and macrofibers, utilizes a multi-scale approach towards crack control and is extended to durability-related applications. Reinforced HyFRC and reinforced concrete beams were exposed to chloride penetration and monitored for corrosion activity for up to two years. Because concrete structures are subjected to various crack-inducing loads while in service, beam specimens in this study were placed under a cyclic, flexural preloading protocol prior to induced corrosion to account for such service conditions. The time to corrosion initiation was found to increase with reduced maximum flexural crack widths and suppression of surface splitting cracks during preloading, both of which were improved by HyFRC compared to concrete. Crack resistance provided by hybrid fiber reinforcement was evident during the corrosion propagation stage, as additional surface cracking was not detected with reinforced HyFRC and residual flexural testing revealed no significant degradation in flexural performance. In contrast, damage to reinforced concrete beams resulted in nearly complete loss of rebar-matrix bond due to extensive splitting crack formation and widening. The results suggest hybrid fiber reinforcement was effective in resisting tensile stresses from mechanical loading and from the internal growth of corrosion products, ultimately limiting the damage to reinforcing steel and maintaining the service capacity of beam elements.
\end{abstract}

\section{INTRODUCTION}

Corrosion of reinforcing steel is an omnipresent issue that limits the useful life of concrete structures. Under normal conditions, steel reinforcing bars in concrete form a corrosion-inhibiting passive film due to the high $\mathrm{pH}$ of the concrete pore solution and are 
physically protected from the external environment. Cracking in the concrete cover, which can occur as a result of service-level loading, increases the permeability of the material, allowing for an expedited ingress of corrosion-inducing agents and shorter time to corrosion initiation $[1,2]$. To improve the longterm durability of reinforced concrete, strategies focused on improving the crack resistance of concrete are desired.

The addition of fibers to cement-based composites has been shown to increase the toughness of the resulting material by arresting crack propagation caused by internal expansive processes [3, 4]. A properly designed fiberreinforced concrete will promote the formation of numerous fine cracks. This multiplecracking behavior allows deformations to occur over a more diffusive volume of concrete and delays concentrated damage typical of large cracks formed in conventional concrete. Hybrid fiber-reinforced concrete (HyFRC), which utilizes two to three fiber types varying in material and dimensions, is highlighted here for its multi-scale approach towards damage resistance. Due to the incorporation of different tiers of fibers, cracking damage in the composite is controlled from microcracking to large macrocracking.

The research presented in this paper investigates the effectiveness of the crack control afforded by HyFRC on the corrosion behavior of reinforced beam elements. In addition, a variant HyFRC designated as selfconsolidating HyFRC (SC-HyFRC) is also considered for study. To account for the effects of concrete cover cracking, flexural preloading of fiber and non-fiber reinforced beam specimens was performed and resulting corrosion rates and corrosion damage were assessed.

\section{MATERIALS AND SPECIMENS}

\subsection{HyFRC}

Proportions of the HyFRC design are presented in Table 1, which are based on the design developed by Blunt and Ostertag [5]. Fiber hybridization was achieved through the use of three types of fibers - 8-mm long polyvinyl alcohol (PVA), 30-mm long hookedend steel, and 60-mm long hooked-end steel. The total fiber volume fraction was set to $1.5 \%$, based on concrete volume. A plain concrete (C) lacking fiber reinforcement was also investigated for study as a reference material for HyFRC to be compared against. Mix proportions for the plain concrete were adopted from a previous corrosion-related study and were developed such that the resulting nominal compressive strength was similar to HyFRC. Casting of the plain concrete was done with two individual batches, resulting in some difference in compressive strength between the two sets.

Table 1: Mix proportions for HyFRC and C (per $\left.1 \mathrm{~m}^{3}\right)$.

\begin{tabular}{lcc}
\hline & HyFRC & C \\
\hline Cement (kg) & 420 & 440 \\
\hline Coarse aggregate (kg) & 780 & 680 \\
\hline Fine aggregate $(\mathrm{kg})$ & 850 & 890 \\
\hline Batched water (kg) & 230 & 240 \\
\hline PVA fibers (vol. \%) & 0.2 & - \\
\hline 30mm Steel fibers (vol. \%) & 0.5 & - \\
\hline 60mm Steel fibers (vol. \%) & 0.8 & - \\
\hline$f_{c}^{\prime}(\mathrm{MPa})$ & 47 & $53^{\mathrm{a}} / 45^{\mathrm{b}}$ \\
\hline \multicolumn{4}{c}{ a - Concrete cast for preloaded beams; } \\
\multicolumn{2}{c}{ - Concrete cast for non-preloaded beams }
\end{tabular}

\subsection{SC-HyFRC}

SC-HyFRC was modified from the aforementioned HyFRC design to allow for self-consolidation behavior, which is further described in [6]. Details of the SC-HyFRC mix proportions are shown in Table 2 . While the total fiber volume fraction was designed to $1.5 \%$, matching that of HyFRC, 60-mm long fibers were not included to improve fresh state flowability. Fly ash constituted $25 \%$ of the total binder mass to partially offset the high carbon emissions of cement, which is typically used in high amounts in self-consolidating mixtures. A control self-consolidating concrete (SCC) was fabricated with the same binder and similar aggregate proportions, as well as the same water-binder ratio $(0.45)$ as SC-HyFRC. 
Table 2: Mix proportions for SC-HyFRC and SCC (per $\left.1 \mathrm{~m}^{3}\right)$.

\begin{tabular}{lcc}
\hline & SC-HyFRC & SCC \\
\hline Cement $(\mathrm{kg})$ & 400 & 400 \\
\hline Fly ash $(\mathrm{kg})$ & 130 & 130 \\
\hline Coarse aggregate $(\mathrm{kg})$ & 420 & 500 \\
\hline Fine aggregate $(\mathrm{kg})$ & 1040 & 1000 \\
\hline Batched water $(\mathrm{kg})$ & 240 & 240 \\
\hline PVA fibers (vol. \%) & 0.2 & - \\
\hline $\begin{array}{l}\text { 30mm Steel fibers } \\
\text { (vol. \%) }\end{array}$ & 1.3 & - \\
\hline $\begin{array}{l}\text { Superplasticizer } \\
\text { (wt. \% of binder) }\end{array}$ & 0.93 & 0.42 \\
\hline $\begin{array}{l}\text { Viscosity modifier } \\
\text { (wt. \% of binder) }\end{array}$ & 2.20 & 0.40 \\
\hline$f_{c}$ (MPa) & 39 & 37 \\
\hline
\end{tabular}

\subsection{Beam specimens}

All concrete types selected for study utilized a common beam design (Figure 1). The concrete was cast into a rectangular prism, with a square cross section of $152 \mathrm{~mm}$ by $152 \mathrm{~mm}$ and a length of $610 \mathrm{~mm}$. Two lengths of A615 steel reinforcing bars, with sizes of No. 3 (9.5 $\mathrm{mm}$ diameter) and No. 6 (19 mm diameter), were longitudinally embedded in the specimen and partially extruded from the cast concrete surface. After sandblasting each bar to remove its mill scale, it was treated such that a central length of $508 \mathrm{~mm}$ was allowed to bond directly to the concrete surface, defining the region of interest for corrosion activity. Surfaces of the bar outside this region were coated with an electrically-insulating lacquer, layered with electrical tape, and finally layered with heatshrunk polyolefin tube to prevent corrosion.

After casting, the specimens were cured in moist conditions for seven days followed by an additional 21 days of curing in ambient laboratory conditions prior to mechanical testing. After pre-cracking the specimens in preparation for induced corrosion experimentation, a polyvinyl chloride dam was affixed to the horizontal surface of the concrete beams nearest the No. 3 rebar to later allow for continuous ponding of sodium chloride solution on the specimen. All vertical concrete surfaces were then coated with a moisture-resistant sealant to prevent solution from escaping through cracks or pores. An external electrical wire connected the No. 3 and No. 6 reinforcing bars, simulating conditions where steel reinforcing bars, which are in electrical contact in a reinforced concrete element due to physical contact, initiate corrosion at different times due to differences in placement depths.

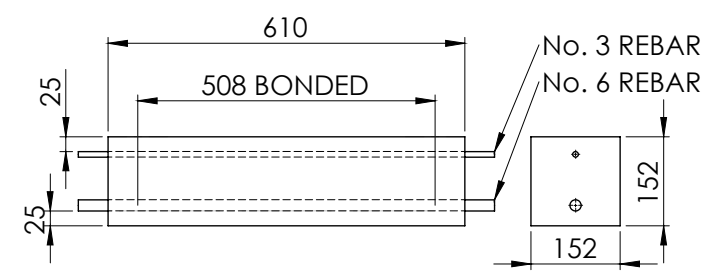

(a)

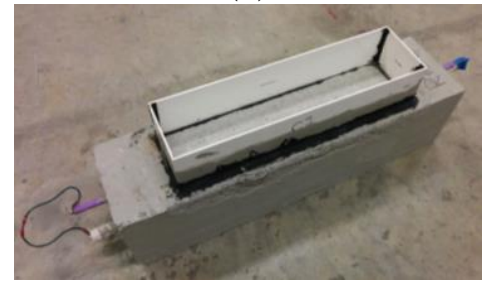

(b)

Figure 1: Beam specimen: (a) Detailing (mm); (b) Finished specimen with ponding dam.

\section{EXPERIMENTAL METHODS}

\subsection{Preload testing}

To induce flexural cracks prior to corrosion experimentation, select beam specimens were subjected to four-point bending tests. The beams were orientated such the concrete nearest the No. 3 rebar was placed in tension, while the concrete nearest the No. 6 rebar was placed in compression. Surface flexural cracks, if any, would thus be located closest to the No. 3 rebar. The beam span was set to $457 \mathrm{~mm}$ with equidistant lengths between loading points. Loading consisted of five consecutive cycles from an unloaded state to a predetermined peak load prior to complete unloading.

\subsection{Corrosion testing}

To corrode the steel within the specimens, 3.5 mass percent sodium chloride solution was allowed to permeate through the concrete matrix over long durations. SC-HyFRC and SCC beams were continuously ponded with the solution while stored in an environmental 
chamber with conditions of $50^{\circ} \mathrm{C}$ and $50 \%$ relative humidity. After 42 weeks, the existing solution in the ponding dam was allowed to evaporate and the specimens remained within the environmental chamber for an additional year prior to termination of the experimental program, simulating extended wetting and drying seasons. The corrosion testing protocol for the HyFRC and concrete beams differed, focusing on corrosion activity in ambient conditions, though subject to a higher frequency of wetting and drying. These beams were initially ponded continuously for 11 weeks prior to enactment of wet-dry cycling, which consisted of one week of drying (complete relief of ponding dam) followed by one week of wetting. The beams were stored in ambient laboratory conditions for the entire duration of testing.

\section{RESULTS AND DISCUSSION}

\subsection{Mechanical response of beams}

Representative load-midpoint displacement responses from four-point bending are plotted in Figure 2, and average damage characteristics of sample sets are detailed in Table 3 and Table 4 for HyFRC and SC-HyFRC experiments, respectively. Specimens are designated by material (concrete (C), HyFRC, SCC, or SCHyFRC) and peak load (in $\mathrm{kN}$ ). The distinct load drops that occur in non-fiber-reinforced specimens are indicative of crack formation. HyFRC-54 exhibits a smooth deflectionhardening response, maintaining stiffness through more severe loading, while SCHyFRC-32 exhibits a nearly linear elastic behavior, with slight residual displacements indicating some damage caused by microcracking.

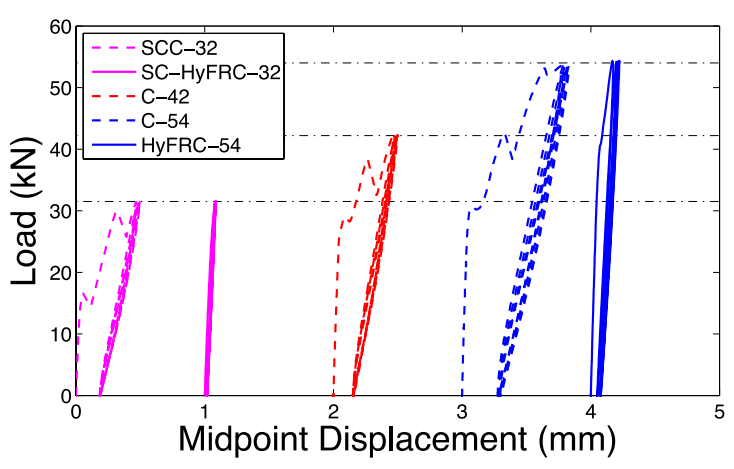

Figure 2: Representative load-midpoint displacement response of preloaded beam specimens.

Table 3: Average damage characteristics of $\mathrm{C}$ and HyFRC specimen sets.

\begin{tabular}{|c|c|c|c|c|}
\hline & $\mathrm{C}-42 \mathrm{f}^{\mathrm{a}}$ & $\mathrm{C}-42 \mathrm{~s}^{\mathrm{b}}$ & C-54 & HyFRC-54 \\
\hline $\begin{array}{l}\text { Max. } \\
\text { disp. } \\
(\mathrm{mm})\end{array}$ & 0.36 & 0.50 & 0.83 & 0.28 \\
\hline $\begin{array}{l}\text { Resid. } \\
\text { disp. } \\
(\mathrm{mm})\end{array}$ & 0.11 & 0.15 & 0.30 & 0.09 \\
\hline $\begin{array}{l}\text { No. } \\
\text { flexural } \\
\text { cracks }\end{array}$ & 2 & 2 & 3 & 1 \\
\hline $\begin{array}{l}\text { Max. } \\
\text { flex. } \\
\text { crack } \\
\text { width }\end{array}$ & 0.19 & 0.17 & 0.29 & 0.04 \\
\hline $\begin{array}{l}\text { Split. } \\
\text { Crack } \\
\text { length } \\
(\mathrm{mm})\end{array}$ & - & 191 & 114 & - \\
\hline $\begin{array}{l}\text { Split. } \\
\text { Crack } \\
\text { width } \\
(\mathrm{mm})\end{array}$ & - & 0.10 & 0.11 & - \\
\hline $\begin{array}{l}a-C-42 \\
b-C-42\end{array}$ & $\begin{array}{l}\text { pecime } \\
\text { pecime }\end{array}$ & $\begin{array}{l}\text { exhibite } \\
\text { exhibite } \\
\text { cracks }\end{array}$ & $\begin{array}{l}\text { only } \\
\text { flexui }\end{array}$ & $\begin{array}{l}\text { Iral cracks. } \\
\text { nd splitting }\end{array}$ \\
\hline
\end{tabular}

Following the preloading protocol, flexural cracks with widths ranging from $0.17 \mathrm{~mm}$ to $0.29 \mathrm{~mm}$ were observed in specimens cast with plain concrete $(\mathrm{C})$. Observable HyFRC surface damage was limited, with residual crack widths on the order of $0.04 \mathrm{~mm}$. Figure 3 shows representative surface damage of select specimens. Given the similarity in maximum displacement between C-42f and HyFRC-54, it can be inferred that multiple microcracks formed in HyFRC-54, though such cracks could 
not be detected due to the fineness of the openings. Additionally, splitting cracks were formed in several of the $\mathrm{C}$ specimens due to the cyclic loading, while splitting cracks were not observed in HyFRC.

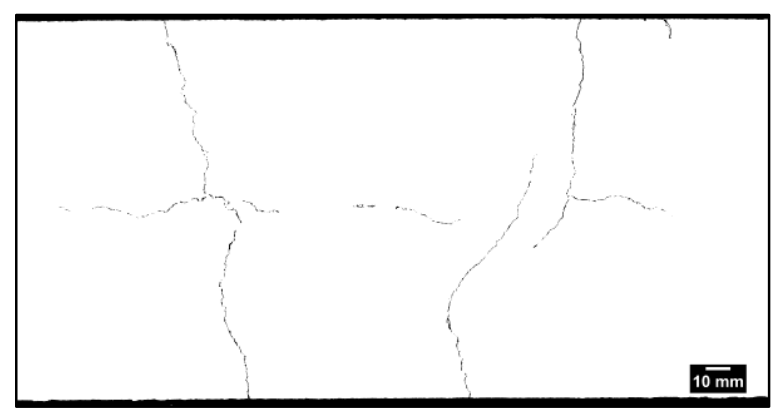

(a)

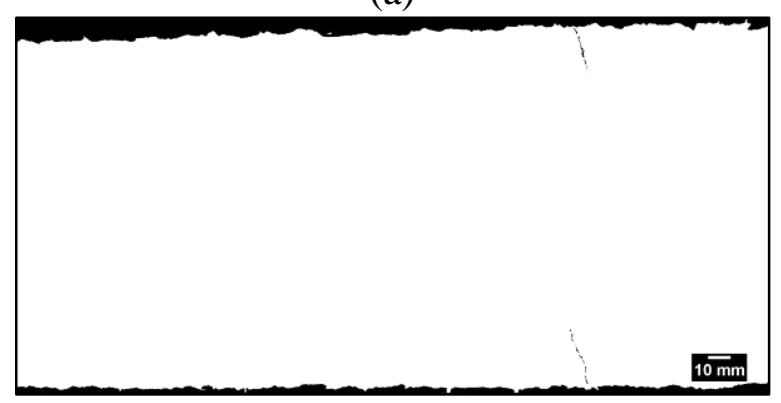

(b)

Figure 3: Representative surface flexural cracking after preloading and prior to corrosion activity: (a) C-54 specimen; (b) HyFRC-54 specimen. Crack widths are enlarged for clarity.

Table 4: Average damage characteristics of SCC and SC-HyFRC specimen sets.

\begin{tabular}{lcc}
\hline & SCC-32 & SC-HyFRC-32 \\
\hline $\begin{array}{l}\text { Max. disp. } \\
(\mathrm{mm})\end{array}$ & 0.40 & 0.10 \\
\hline $\begin{array}{l}\text { Resid. disp. } \\
(\mathrm{mm})\end{array}$ & 0.16 & 0.02 \\
\hline $\begin{array}{l}\text { No. flexural } \\
\text { cracks }\end{array}$ & 2 & 0 \\
\hline $\begin{array}{l}\text { Max. flex } \\
\text { crack width } \\
\text { (mm) }\end{array}$ & 0.26 & - \\
\hline $\begin{array}{l}\text { Split. Crack } \\
\text { length } \\
\text { (mm) }\end{array}$ & 200 & - \\
\hline $\begin{array}{l}\text { Split. Crack } \\
\text { width (mm) }\end{array}$ & 0.09 & - \\
\hline
\end{tabular}

When subjected to peak loads of $32 \mathrm{kN}$, specimens cast with plain self-consolidating concrete (SCC) displayed cracking similar to that of the (C) specimens, with residual flexural crack width sizes in the range of 0.14 to 0.19 $\mathrm{mm}$, and the cycling loading protocol was sufficient to produce splitting cracks in all SCC specimens (Table 4). SC-HyFRC specimens loaded to the same peak exhibited no detectable flexural or splitting cracks, owing to the effectiveness of the crack control provided by hybrid fiber reinforcement.

\subsection{Corrosion behavior of beams}

Measurements of the corrosion current density $\left(i_{c o r r}\right)$ of the No. 3 reinforcing bar nearest the ponding surface of the beams are presented in Figure 4 and Figure 5 for HyFRC and SC-HyFRC experiments, respectively. As described in the literature, the threshold for corrosion initiation may be taken as $0.1 \mu \mathrm{A} / \mathrm{cm}^{2}$ [7]. In both HyFRC and SC-HyFRC, crack control during applied loading exhibited a strong influence on the time to corrosion initiation. HyFRC-54 maintained a passive state for 62 weeks, demonstrating the longest time to corrosion initiation of the $\mathrm{C}$ and HyFRC specimens. It is noted that calculated values of $i_{\text {corr }}$ are generally similar to the initially uncracked HyFRC-0 samples, suggesting fine induced cracks less than $0.05 \mathrm{~mm}$ have negligible effects on permeability; this is consistent with research performed elsewhere $[1,8]$. These results are echoed in the case of SC-HyFRC-32, where aside from initial fluctuations, the No. 3 bar maintained a state of passivity through the 42 -week sampling period. This behavior was matched by SC-HyFRC-0 and was contrasted by the SCC-32 specimens, which showed higher sensitivity to the initial cracking imposed by the preloading conditions and began actively corroding very early in the experiment.

The formation of a splitting crack amongst C-42, C-54 and SCC-32 specimens showed a considerable influence on corrosion behavior. The factor is isolated in the curves of C-42f, which showed only flexural cracking and $\mathrm{C}$ $42 \mathrm{~s}$, which showed both flexural cracks and a splitting crack longitudinally along the rebar. C-42s entered a stated of active corrosion 18 
weeks earlier than $\mathrm{C}-42 \mathrm{f}$, likely due to the splitting crack that formed, creating a path for chlorides to reach the reinforcing steel more easily. Bending stresses cause the ribs of the deformed steel reinforcing bar to bear on the surrounding matrix, producing tensile stresses in the material surrounding the bar. This will cause concrete to crack once its tensile strength is exceeded [9]. C-42s depassivated contemporaneously with C-54, which also had a splitting crack. This serves to verify that the existence of a splitting crack governed the initiation of corrosion in the specimens without fiber reinforcing. Both HyFRC-54 and SCHyFRC-32 were able to prevent the formation of splitting cracks, which proved in both sample sets to be valuable in extending the initiation period.

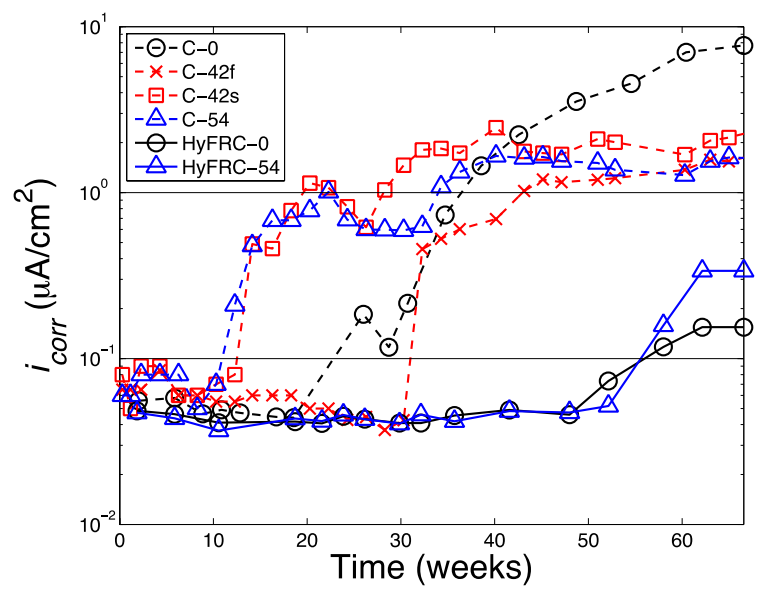

Figure 4: Corrosion current density of No. 3 reinforcing bar in $\mathrm{C}$ and HyFRC specimen sets.

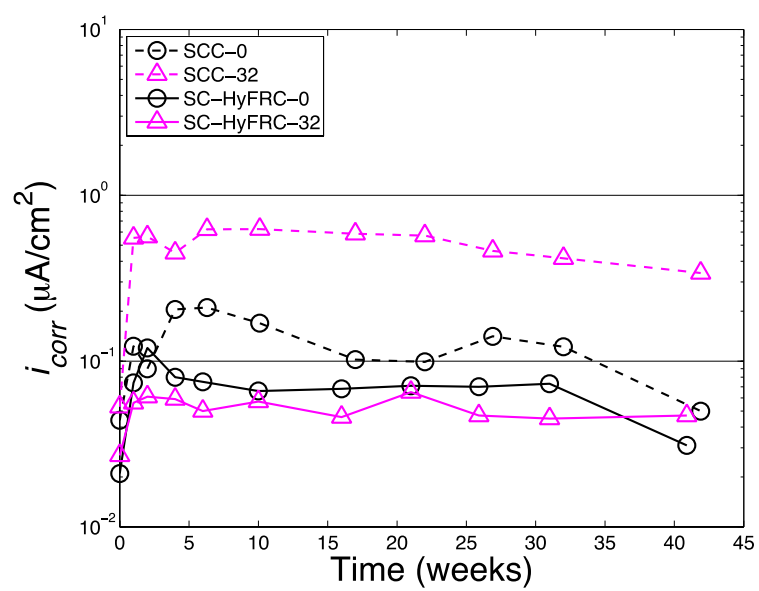

Figure 5: Corrosion current density of No. 3 reinforcing bar in SCC and SC-HyFRC specimen sets
Splitting cracks were formed in all preloaded SCC specimens, while none formed in SC-HyFRC specimens. It follows that without crack control during preloading, chlorides can easily access and attack the reinforcing steel, leading to a more rapid onset of active corrosion. Within one week, SCC-32 specimens exhibited depassivation, indicated by a corrosion current density above the threshold of $0.1 \mu \mathrm{A} / \mathrm{cm}^{2}$. SCC-0 and all SCHyFRC samples remained passive at this point. Measurements in the following weeks show the continued passivation of the embedded reinforcing bars in those samples not displaying cracking. While SCC-0 crosses the threshold, it is unable to maintain this corrosion rate. One explanation for the observed decrease in corrosion current density over the ponding period for all SCC and SC-HyFRC specimens is the loss of available oxygen at the bar surface due to continuous ponding, which would lead to a lower corrosion rate [10].

\subsection{Destructive testing of SCC and SC-HyFRC beams}

Details on cracking patterns and corrosion current densities for all SCC and SC-HyFRC specimens at the end of the two-year corrosion study can be found in Table 5. During this period, chloride ions were able to migrate to the depth of the top reinforcing bar in all SCC and SC-HyFRC samples thus terminating the initiation phase and starting the propagation phase of corrosion damage. The influence of fiber-reinforcing in the concrete matrix was again realized during this period. Splitting cracks were developed in all SCC-0 samples, while the splitting cracks of SCC-32 samples were observed to both grow in width along the top face and extend deeper into the beam cross section. Splitting cracks in SCC-32 specimens reached the depth of the bottom-reinforcing bar, and even to the bottom face of beam specimens; corrosion damage was subsequently observed at the bottom reinforcement. No evidence of corrosion-induced cracking was observed amongst SC-HyFRC specimens. 
Table 5: Average final damage characteristics of SSC and SC-HyFRC specimen sets at conclusion of corrosion-induced experimentation.

\begin{tabular}{lllll}
\hline & $\begin{array}{l}\text { Top } \\
\text { face } \\
\text { dmg. }\end{array}$ & $\begin{array}{l}\text { Top } \\
\text { bar } i_{\text {corr }} \\
\left(\mu \mathrm{A} / \mathrm{cm}^{2}\right)\end{array}$ & $\begin{array}{l}\text { Bot. } \\
\text { face } \\
\text { dmg. }\end{array}$ & $\begin{array}{l}\text { Bottom } \\
\text { bar } i_{\text {corr }} \\
\left(\mu \mathrm{A} / \mathrm{cm}^{2}\right)\end{array}$ \\
\hline SCC-0 & $\begin{array}{l}\text { Split. } \\
\text { crack }\end{array}$ & 2.80 & - & $<0.1$ \\
\hline SCC-32 & $\begin{array}{l}\text { Flex. } \\
\text { crack; }\end{array}$ & 6.05 & $\begin{array}{l}\text { Split. } \\
\text { crack }\end{array}$ & 21.95 \\
& $\begin{array}{l}\text { Split. } \\
\text { crack }\end{array}$ & & & \\
& - & 0.43 & - & $<0.1$ \\
\hline SC- & - & & \\
HyFRC- & & & & $<0.1$ \\
0 & & & & \\
\hline $\begin{array}{l}\text { SC- } \\
\text { HyFRC- }\end{array}$ & & 0.40 & & \\
32 & & & & \\
\hline
\end{tabular}

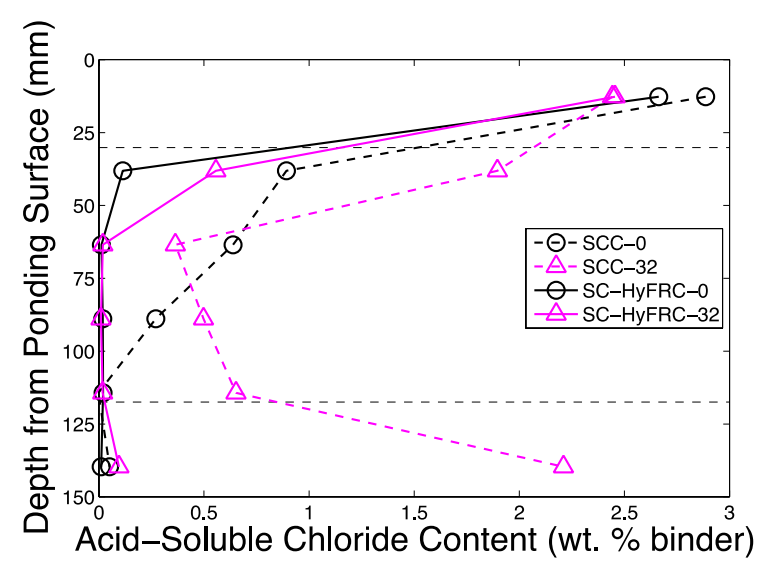

Figure 6: Chloride content profile from extracted core samples of SCC and SC-HyFRC beam specimens. Centerline depth of steel reinforcing bars shown as dashed horizontal lines.

Chloride analysis in accordance with ASTM C1152 was performed on SCC and SC-HyFRC, with the results shown Figure 6. The existence of a splitting crack that penetrated through the full depth of the SCC-32 specimens allowed for the transport of chlorides throughout the cross section. The SCC-0 specimens show a profile indicating that chlorides travelled through a corrosion-induced splitting crack and were subsequently able to reach a level just above the bottom-reinforcing bar, where the splitting crack was arrested. In all SC-HyFRC specimens, chloride content was negligible below the top reinforcing bar, as is expected due to the lack of splitting cracks in these specimens. It can be noted that chloride ions were able to penetrate deeper into SC-HyFRC32 than in SC-HyFRC-0 specimens. This indicates the presence of microcracking in the fiber-reinforced matrix, which is expected due to the existence of small residual displacements and thus slight non-linear behavior.

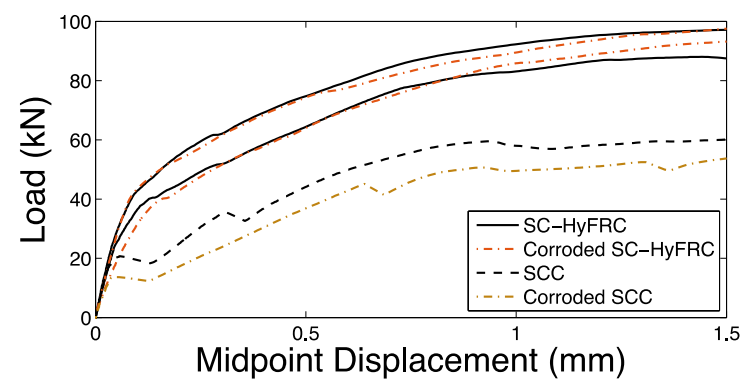

Figure 7: Residual monotonic load capacity of SCC and SC-HyFRC beam specimens

Residual capacity testing was performed via monotonic four-point bending tests. Undamaged, uncorroded specimens (designated as "SC-HyFRC" and "SCC") are compared with SC-HyFRC-32 and SCC-0 (designated as "Corroded SC-HyFRC" and "Corroded SCC", respectively) in Figure 7. SCC-32 specimens could not be tested due to instability caused by excessive damage, and differences in residual performance between SC-HyFRC-0 and SC-HyFRC-32 were negligible, and thus SC-HyFRC-0 were omitted. SCC-0 beams exhibited reduced flexural stiffness as could be expected based on the formation of corrosion-induced splitting cracks. SCC-0 showed a decrease in flexural stiffness of $33 \%$, while flexural crack formation occurred at $35 \%$ lower load. Due to the dependence of the peak load on the bond between the reinforcing steel and the surrounding matrix, this loss in strength is expected due to the growth of the splitting cracks and subsequent slippage of the reinforcing steel. Neither the introduction of reinforcement corrosion nor preloading plus subsequent corrosion in the SC-HyFRC beams influenced the load at which crack formation was visible at the surface, relative to uncorroded samples, and deflection hardening behavior was maintained to loads in excess of $80 \mathrm{kN}$. Experimental variation in load- 
deflection behavior during monotonic four point bending of two SC-HyFRC and two corroded SC-HyFRC beams is shown in Figure 7 , demonstrating the scatter observed during beam testing.

Table 6: Maximum gravimetric losses of reinforcing bars from SCC and SC-HyFRC specimen sets.

\begin{tabular}{lcc}
\hline & $\begin{array}{l}\text { Top bar } \\
\text { mass loss }(\mathrm{g})\end{array}$ & $\begin{array}{l}\text { Bottom bar } \\
\text { mass loss }(\mathrm{g})\end{array}$ \\
\hline SCC-0 & 8 & 20 \\
\hline SCC-32 & 12 & 112 \\
\hline SC-HyFRC-0 & 2 & 1 \\
\hline SC-HyFRC-32 & 4 & 1 \\
\hline
\end{tabular}

Gravimetric loss was measured for top and bottom bars in the SCC and SC-HyFRC beams and the results are presented in Table 6. As evidenced by the chloride analysis data, as well as electrochemical measurements following the conclusion of corrosion monitoring, the No. 6 bar in the SCC samples was exposed to chlorides and in the case of SCC-32, was actively corroding. Gravimetric mass loss data showed that the bottom bar of SCC-32 specimens underwent the most severe corrosion, losing a maximum of ten percent of its total mass. While mass loss is distributed across the bar length there is a notable concentration in the region associated with the transverse cracks formed during the application of mechanical loading. Distribution of mass loss in the top bars of SC-HyFRC beams was less uniform, with some locations showing no evidence of corrosion. Overall, corrosion of steel in HyFRC beams was light in comparison, with the bottom bars showing negligible damage.

\section{CONCLUSION}

The enhanced crack control of hybrid fiberreinforced concrete (HyFRC) and selfconsolidating hybrid fiber-reinforced concrete (SC-HyFRC) was able to mitigate corrosion damage in pre-damaged reinforced concrete beams. The conclusions are as follows:

1. Fiber reinforcing is effective at delaying flexural crack formation and limiting crack growth, as observed in both HyFRC and SC-HyFRC beams compared to their non-fiber reinforced concrete counterparts under similar loading conditions. While microcracking undoubtedly increased the permeability of the cover composite, there was still a significant delay in corrosion initiation compared to reinforced concrete without fibers, with the preloaded, cracked HyFRC and SCHyFRC behaving similarly to nonloaded HyFRC and SC-HyFRC specimens.

2. The presence of a surface splitting crack was found to expedite the time to corrosion initiation considering beam specimens cast with plain concrete. Hybrid fiber reinforcement was effective in suppressing splitting cracks during preloading, further improving the delay in active corrosion provided by HyFRC and SC-HyFRC.

3. Once corrosion has begun to propagate, fiber reinforcement continues to protect the concrete cover from crack formation and crack growth, slowing the rate of corrosion propagation.

4. In SC-HyFRC beams, the resistance of the cover to cracking ultimately resulted in delayed time to corrosion initiation, slowed ingress of $\mathrm{NaCl}$ solution, lower corrosion rate, reduced mass loss of reinforcing steel, and better residual flexural capacity at the end of a two year testing period.

The results of this study indicate that cracked, or microcracked hybrid fiberreinforced composites, due to their enhanced crack control, perform better than their cracked and uncracked concrete counterparts when exposed to a corrosive environment and when exposed to combined mechanical and environmental loading due to a corrosive environment. 


\section{ACKNOWLEDGEMENTS}

This work was supported by the Federal Highway Administration (FHWA) through grant DTFH61-09-R-00017.

\section{REFERENCES}

[1] Sahmaran, M., and Yaman, I.O. 2008. Influence of transverse crack width on reinforcement corrosion initiation and propagation in mortar beams. Can J Civ Eng, 35(3):236-45.

[2] Mohammed, T.U., Otsuki, N., and Hamada, H. 2003. Corrosion of steel bars in cracked concrete under marine environment. J Mater Civ Eng, 15(5):4609.

[3] Yi, C.K., and Ostertag, C.P. 2005. Mechanical approach in mitigating alkalisilica reaction. Cem Concr Res, 35(1):6775 .

[4] Grubb, J.A., Blunt, J., Ostertag, C.P., and Devine, T.M. 2007. Effect of steel microfibers on corrosion of steel reinforcing bars. Cem Concr Res, 37(7):1115-26.

[5] Blunt, J., and Ostertag, C.P. 2009. Performance-based approach for the design of a deflection hardened hybrid fiberreinforced concrete. $J$ Eng Mech, 135(9):978-86.

[6] Jen, G., Trono, W., and Ostertag, C.P. 2016. Self-consolidating hybrid fiber reinforced concrete: Development, properties and composite behavior. Constr Build Mater, 104:63-71.

[7] Andrade, C., and Alonso, C. 1996. Corrosion rate monitoring in the laboratory and on-site. Constr Build Mater, 10(5):315-28.

[8] Wang, K., Jansen, D.C., Shah, S.P., and Karr, A.F. 1997. Permeability study of cracked concrete. Cem Concr Compos, 27(3):381-93.

[9] Goto, Y. 1971. Cracks formed in concrete around deformed tension bars. ACI J Proc, 68(4):244-51.
[10] Ahmad, S. 2003. Reinforcement corrosion in concrete structures, its monitoring and service life prediction-a review. Cem Concr Compos, 25(4-5):459-71. 